\title{
The synthesis of polystyrene with a new chemical approach
}

\author{
Naima Bensaada ${ }^{* a b}$, Moulkheir Ayat ${ }^{\mathrm{a}}$, Rachid Meghabar ${ }^{\mathrm{a}}$ and Mohammed Belbachir ${ }^{\mathrm{a}}$
}

${ }^{a}$ Laboratory of Polymer Chemical, Department of Chemistry, Faculty of Exact and Applied Sciences, University of Oran1 Ahmed Benbella, 31100 Oran, Algeria

${ }^{b}$ Preparatory School in Sciences and Technology. Oran, Algeria

\begin{tabular}{l}
\hline C H R O N I C L E \\
\hline Article history: \\
Received October 21, 2014 \\
Received in revised form \\
January 29, 2015 \\
Accepted 8 March 2015 \\
Available online \\
8 March 2015 \\
\hline Keywords: \\
Polymerization \\
Polystyrene \\
Montmorillonite \\
Maghnite-Na \\
\end{tabular}

\section{A B S T R A C T}

The bulk room-temperature polymerization of styrene initiated by environmentally friendly
catalysts Maghnite- $\mathrm{Na}^{+}$is investigated. The catalyst removed from the reaction mixture simply
by filtration could be regenerated and reused. The effect of the Maghnite- $\mathrm{Na}^{+}$catalyst loading
on degree of polymerization had been studied and state their inverse relation. The catalyst was
characterized by X-ray diffraction and FTIR spectroscopy.

\section{Introduction}

Green chemistry is focused to use new chemical approaches to reduce waste and toxic effluents. Therefore, it can minimize damage to the environment and helps us improve the quality of life. That is why the use of new inflammable and recyclable solvents ${ }^{1}$ and initiators ${ }^{2}$ is the concept of several researches and syntheses. The polymerization of styrene could be realized according to different approaches in various solvents and initiators. Cationic route developed by Biedron et al. ${ }^{3}$, radical route by Ma et al. ${ }^{4}$, polymerization mediated by transition metal-based catalysts by Mastrolliri et al. ${ }^{5}$ and the anionic route by Vijayaraghavan et al. ${ }^{6}$ and Marechal et al. ${ }^{7}$ are some recently completed works. Utilization of organic solvents and expensive initiators, as well as the requirement of low reaction temperatures, are significant limitations of commotional synthesis of polystyrene. The possibility to achieve a quantitative polymerization of styrene with no solvent used, at room temperature, initiated by inexpensive and recyclable catalysts are the main targets recognized in intention to tremendously decrease the cost of polystyrene synthesis.

* Corresponding author.

E-mail address: bensaadanaima@yahoo.fr (N. Bensaada) 
This paper is focused on the possibility to initiate the polymerization of styrene at room temperature in bulk via sodium-exchange montmorillonite clay "Maghnite-Na+", a new nontoxic recyclable catalyst ${ }^{10}$. The clay, which has been used as catalyst, is produced by a company known as ENOF Maghnia, [MAGHNIA is a city located in the west of Algeria]. It is a montmorillonite clay, which belongs to the family of phyllosilicates. Its structure is an octahedral laminated sheet, sandwiched between tetrahedral silicate layers, and it has an excellent cation exchange property (Fig. 1).

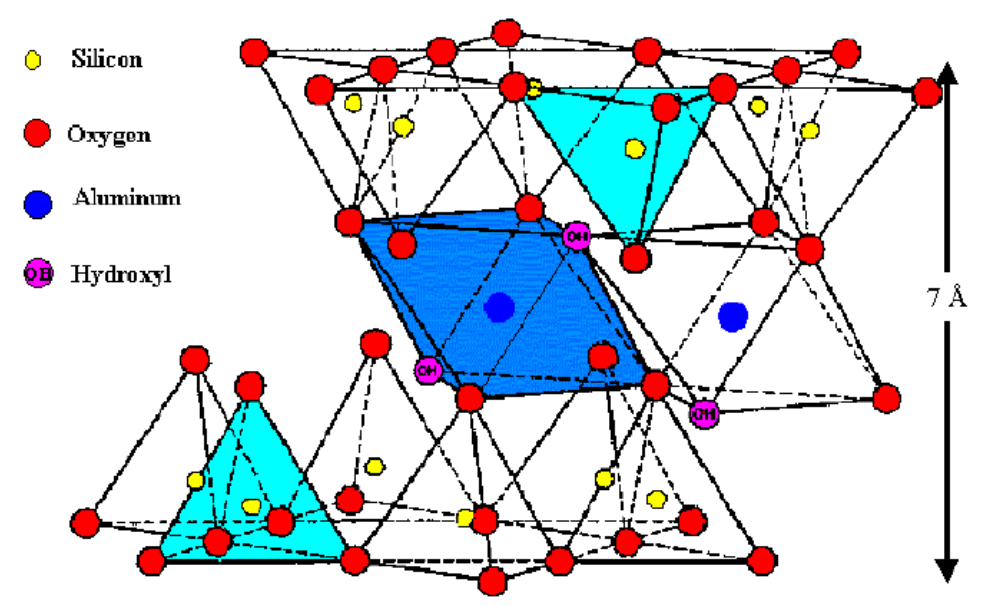

Fig. 1. The montmorillonite clay structure

Herein we are focused on demonstration of the viability of the Maghnite-Na+ clay used as a solid catalyst and initiator of the polymerization processes.

\section{Results and discussion}

The polymerization of styrene has been reported in several recent works using different solvent with various initiator ${ }^{6-7}$. In this paper, we try to use Maghnite- $\mathrm{Na}^{+}$, an environmentally and non-toxic catalyst, to initiate the heterogeneous solvent free room temperature polymerization of styrene (See Scheme 1). We assumed that polymerization reaction runs according to classical well established cationic mechanism.

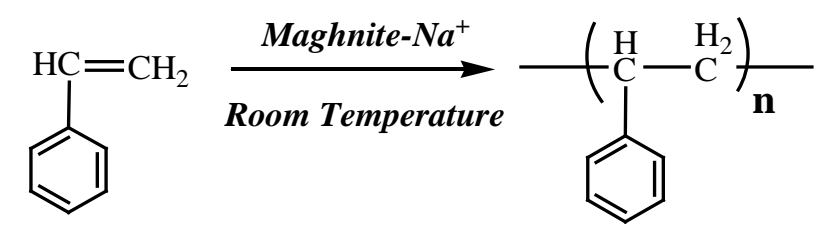

Scheme 1. Polymerization of Styrene.

\subsection{Catalyst}

The IR and XRD analysis of used " Maghnite-Na"', clay show that the structure and the composition of the catalyst were similar as reported in previous work ${ }^{10}$. We suppose that sodium-exchange of " rawMaghnite” reduces the octahedral content $\left(\mathrm{Al}_{2} \mathrm{O}_{3}\right)$, which causes an increase in the proportion of silica.

\subsubsection{FTIR Analysis}

FTIR spectrum shows characteristics bands of montmorillonite clay and the results are comparable to other types of montmorillonite clay. ${ }^{10}$

FTIR spectrum (Fig. 2) shows the following bands: bands between $3388-3619 \mathrm{~cm}^{-1}$ are assigned to AlAlOH coupled by AlMgOH stretching vibrations. The bands between 1113 and $980 \mathrm{~cm}^{-1}$ are 
attributed to Si- O out of plane and $\mathrm{Si}-\mathrm{O}-\mathrm{Si}$ (2 bands) in plane stretching. The deformation bands at 914 $\mathrm{cm}^{-1}, 792 \mathrm{~cm}^{-1}$ and $616 \mathrm{~cm}^{-1}$ are assigned to AlAlOH, $\mathrm{AlFe}^{3+} \mathrm{OH}$ and AlMgOH, respectively. The band at $514 \mathrm{~cm}^{-1}$ is attributed to either Al-OH or Si-O bending and / or Al-O stretching vibration. The band at $449 \mathrm{~cm}^{-1}$ is assigned to Si-O-Al and Si-O-Mg coupled by $\mathrm{OH}$ vibration or Si-O bending vibrations.

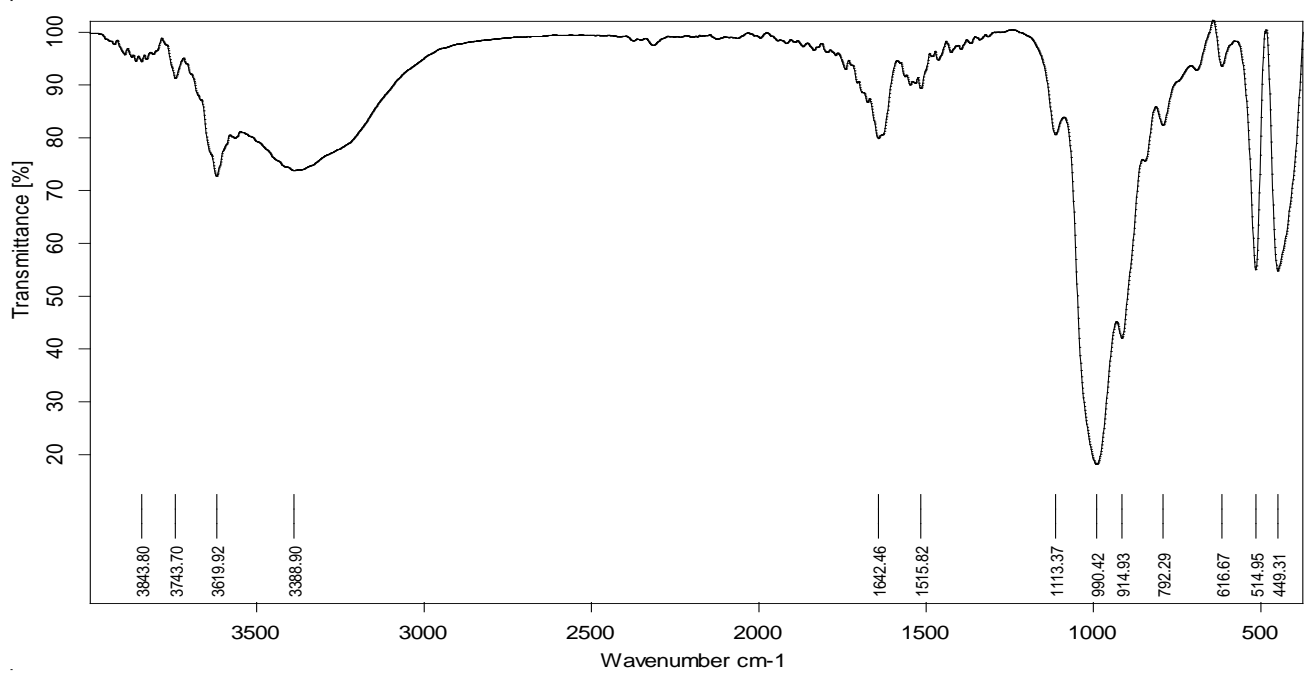

Fig. 2. IR spectrum of Maghnite-Na ${ }^{+}$

\subsubsection{XRD Analysis}

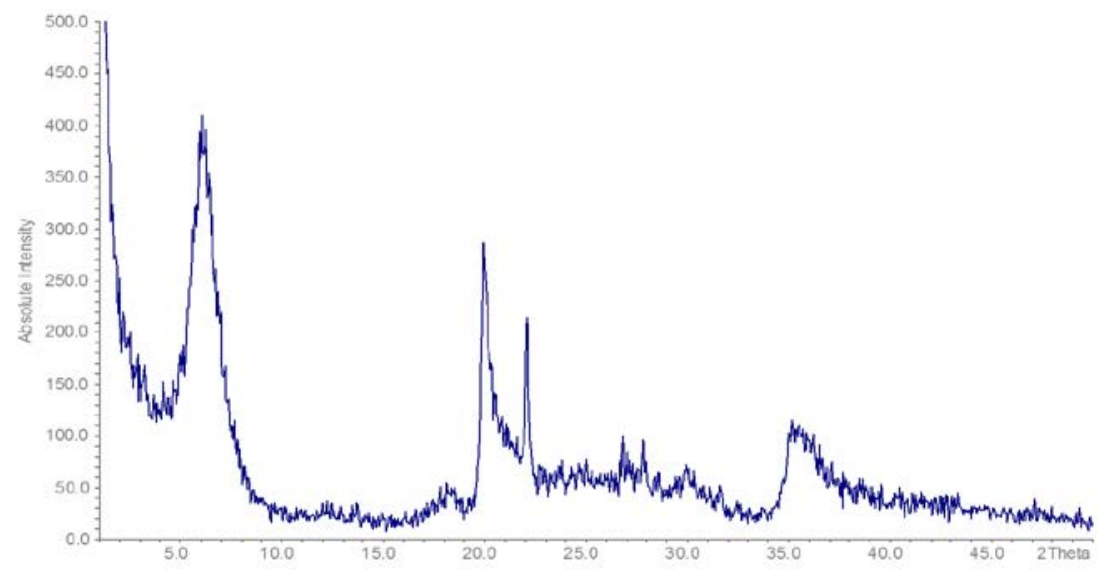

Fig. 3. XRD pattern of Maghnite-Na ${ }^{+}$

Fig. 3 shows the XRD pattern of Maghnite- $\mathrm{Na}^{+}$. The results of basal spacing of the clay are calculated from the XRD peak position using Bragg's equation and are listed in Table 1. The obtained data show that Maghnite- $\mathrm{Na}^{+}$is a montmorillonite clay.

Table 1. RX characteristic of Maghnite- $\mathrm{Na}^{+}$

\begin{tabular}{cccc}
\hline Sample & $\mathbf{d}_{\mathbf{h k l}} \mathbf{( A}^{\mathbf{0}} \mathbf{)}$ & hkl & Nature of sample \\
\hline Maghnite-Na & ${ }^{+}$ & 001 & Montmorillonite \\
& 14.71 & 110 & Montmorillonite \\
& 4.43 & - & Quartz \\
& 4.02 & - & Quartz \\
3.32 & - & Feldspath \\
& 3.20 & - & Calcite \\
2.97 & 200 & Montmorillonite \\
2.54 & 009 & Montmorillonite \\
- & 060 & Montmorillonite \\
\hline
\end{tabular}




\subsection{Polymer characterization}

The characterization of the synthesized product was carried out by means of ${ }^{1} \mathrm{H}$ NMR, gel permeation chromatography (GPC) and by differential scanning calorimetry (DSC).

\subsection{1. ${ }^{1} \mathrm{H}$ NMR Analysis}

${ }^{1} \mathrm{H}$ NMR spectrum of polymer was recorded in $\mathrm{CDCl}_{3}$ using a Brucker $\mathrm{AM} 300 \mathrm{MHz}$ apparatus at $25^{\circ} \mathrm{C}$ and gives the following information:

The ${ }^{1} \mathrm{H}$ NMR spectrum confirms the structure of the polymer obtained in this study. The signals between 6.92 and $7.35 \mathrm{ppm}$ are attributed to the aromatic protons; the signals observed at 6.61 and 6.81 ppm are assigned to the vinylic hydrogens; the signals between $0.95-1.81 \mathrm{ppm}$ are assigned to methine, methylene and methyl protons of the polymer repeating unit (Fig. 4).

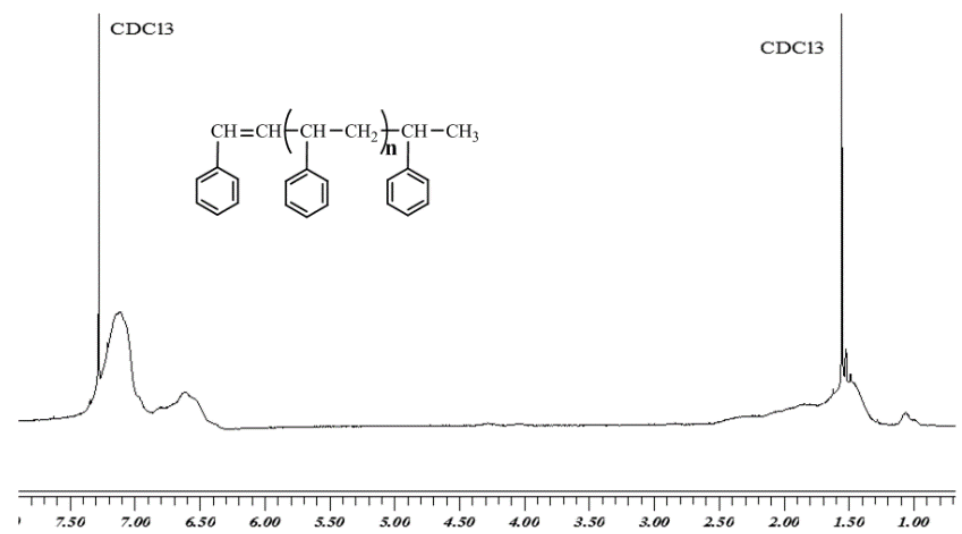

Fig. 4. ${ }^{1} \mathrm{H}$ NMR spectrum of a sample of obtained polystyrene.

\subsection{2. $\quad$ GPC and intrinsic viscosity Analysis}

Table 2 indicates that the molecular weight of obtained products increased when the amount used Maghnite- $\mathrm{Na}^{+}$decreased. It has been shown also that the polymerization rate increased with the amount of Maghnite- $\mathrm{Na}^{+}$.Those dependences clearly support the assumption that Maghnite- $\mathrm{Na}^{+}$act as a catalyst. This phenomenon is probably the result of number of "initiating active sites" responsible of inducing polymerization, a number that is prorate to the catalyst amount used in the reaction. ${ }^{11}$

Table 2. Effect of the amount of Maghnite- $\mathrm{Na}^{+}$on the polymerization of styrene

\begin{tabular}{cccccc}
\hline Maghnite-Na ${ }^{+} /$St weight ratio (\%) & Time (min) & Yield (\%) & Mn $^{\mathbf{a}}$ & $\mathrm{Mw}^{\mathbf{a}}$ & $\mathrm{I}^{\mathbf{b}}$ \\
\hline 5 & 300 & 20 & 2800 & 4612 & 1.64 \\
10 & 60 & 37 & 1532 & 3621 & 1.76 \\
15 & 10 & 56 & 1309 & 2465 & 1.88 \\
20 & spontaneous & 48 & 1166 & 2277 & 1.95 \\
\hline
\end{tabular}

a determined by GPC with polystyrene standard; ${ }^{\mathbf{b}} \mathrm{I}$ - polydispersity index $(\mathrm{Mw} / \mathrm{Mn})$;

\subsubsection{DSC Analysis}

The DSC thermogram of polystyrene (Fig. 5) shows the glass transition temperature $\mathrm{Tg}$ at $81,1^{\circ} \mathrm{C}$ is smaller than the one in the literature. ${ }^{12}$ It is well known that the polystyrene glass transition temperature $T g$ is almost constant for molecular weight $(\mathrm{Mn})$ over $10^{5} \mathrm{~g} \mathrm{~mol}^{-1}$. Below this value, the glass transition temperature starts to decrease, following an empirical relation such as:

$$
T g=T_{g}^{\infty}-\frac{C}{M n}
$$


where $C$ is a constant ( $1.2 \times 10^{5}$ for PS) and $T_{g}^{\infty}$ refers to the $T g$ for very large $M n .{ }^{13}$ As a consequence of Eq. (1), we attribute the decrease in glass transition temperature observed to the reduction in polystyrene molecular weight formed via the polymerization in the presence of Maghnite- $\mathrm{Na}^{+}$.

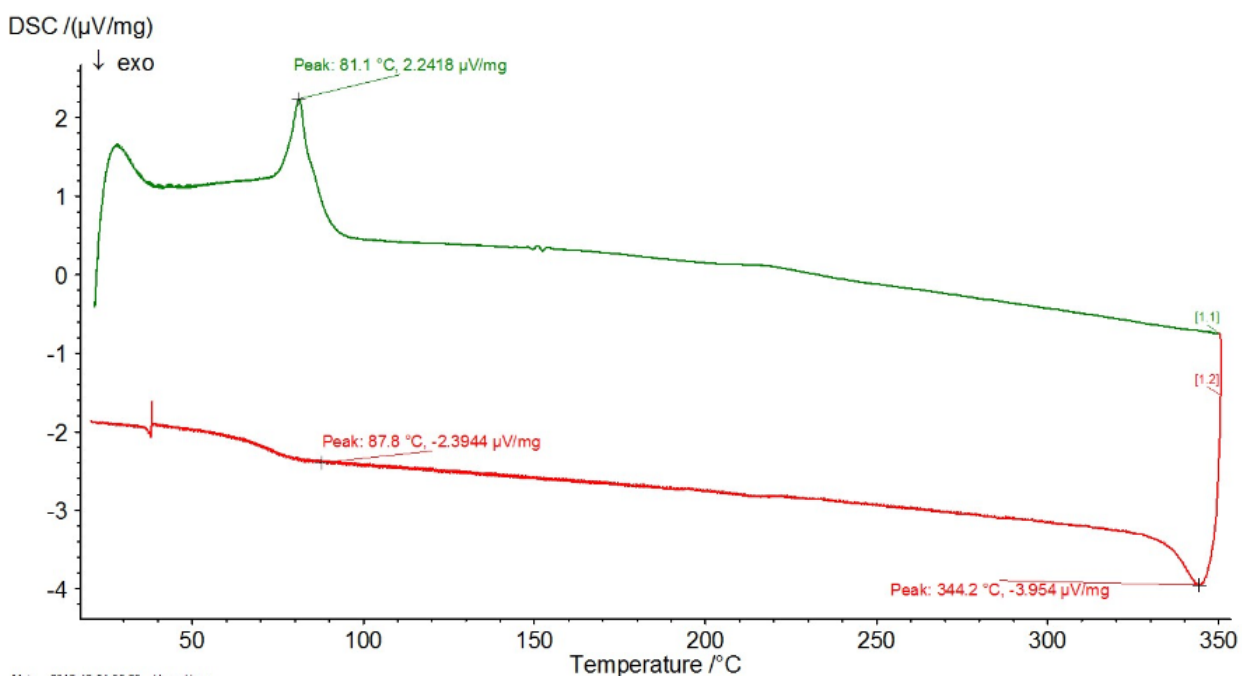

Fig. 5. DSC curve of polystyrene (Maghnite- $\mathrm{Na}^{+} /$St Weight ratio (20 \%).

\section{Conclusions}

This paper has described a method of bulk and room-temperature styrene polymerization initiated by solid and non-toxic Maghnite- $\mathrm{Na}^{+}$clay. IR and XRD analysis have proven that the Maghnite- $\mathrm{Na}^{+}$ belonged to the family of montmorillonite. The polymerization was found to be initiated by Maghnite$\mathrm{Na}^{+}$powder. It has been shown that the polymerization rate increased in line with the amount of used Maghnite- $\mathrm{Na}^{+}$, which clearly shows the catalytic effect of Maghnite- $\mathrm{Na}^{+}$. The structure of the polymer is confirmed with ${ }^{1} \mathrm{H}$ NMR spectra. The decrease in glass transition temperature of polystyrene was attributed to the reduction in polystyrene molecular weight formed via the polymerization in the presence of Maghnite- $\mathrm{Na}^{+}$. Obtained results may have a potential value for environmentally friendly polystyrene production and the method will be explored deeply in forthcoming works.

\section{Acknowledgement}

The authors would like to thank Dr. Ahmed Bensaada (Montreal) for helpful suggestions during the preparation of this paper.

\section{Experimental}

\subsection{General}

Styrene (99\%, from Aldrich) was dried over magnesium sulfate $\left(\mathrm{MgSO}_{4}\right)$ overnight. Methanol and Dichloromethane, (Aldrich Chemical) was used as received. The raw montmorillonite clay was obtained from ENOF Maghnia (Algeria). X-ray diffraction (XRD) analysis of Maghnite- $\mathrm{Na}^{+}$were obtained by using a Philips PW 1880 powder diffractometer using Cu-K $\alpha$ radiation $(\lambda=1.541 \AA)$. Infrared Spectoscopy (FTIR) spectra were recorded on an ATI Mattson FTIR no.9501165. Ten scans were averaged at a resolution of $4 \mathrm{~cm}^{-1}$ for the solid tested of sodium montmorillonite prepared as $\mathrm{KBr}$ pellets (ca.3\% by mass in $\mathrm{KBr}$ ). ${ }^{1} \mathrm{H} N \mathrm{NR}$ spectra were recorded under ambient temperature on an AM 300 FT Bruker spectrometer using tetramethylsilane as internal standard and deuterated chloroform as solvent. Gel permeation chromatography (GPC) measurements of the polymer were carried out using a WISP 712, Waters Associates chromatograph, THF was used as solvent and the instrument was calibrated to a first approximation with polystyrene of known molecular weight. Differential Scanning Calorimetry (DSC) measurements were carried out on a NETZSCH DSC 204 F1 instrument, according 
to the following program: the specimens were heated from ambient temperature to $350{ }^{\circ} \mathrm{C}$ at 10 ${ }^{\circ} \mathrm{C}$,/min, maintained at this temperature during 5 minutes, then cooled to $25^{\circ} \mathrm{C}$ at $20^{\circ} \mathrm{C} / \mathrm{min}$.

\subsection{Preparation of Maghnite- $\mathrm{Na}^{+}$}

The raw-Maghnite (250g) was crushed for 20 min using a Prolabo ceramic balls grinder and dried by baking at $105^{\circ} \mathrm{C}$ for 2 hours. It was subsequently weighed and placed in an erlenmeyer flask together with $1980 \mathrm{~mL}$ of distilled water. The suspension solution was first stirred using a magnetic stirrer for 2 hours and then combined, at room temperature, with $20 \mathrm{ml}(1 \mathrm{M})$ of sodium hex-phosphate, until saturation, which is achieved after 2 days. The mixture was placed into a test tube and let stand for 24 hours. The suspended product is sulfonated. Complete the test tube with distilled water (same volume) and shake. This operation is repeated every 24 hours for a week. Sodium montmorillonite is recovered by centrifugation, washed several time with distilled water and finally dried at $105^{\circ} \mathrm{C}$ for 24 hours.

\subsection{Polymerization procedures}

The polystyrene was obtained by using 9,61 mmol (1 g) of styrene and various amounts of Maghnite-Na ${ }^{+}$(5, 10, 15 and $\left.20 \% \mathrm{wt}\right)$. The mixtures were stirred with a magnetic stirrer at room temperature. After few time, the product was dissolved in $10 \mathrm{ml}$ of dichloromethane. The catalyst was removed from the product by filtration. Subsequently, the filtrate was precipitated by $100 \mathrm{ml}$ of cold methanol to afford a white solid. The precipitated polystyrene was then filtrated and dried in vacuum. The monomer conversion was determined gravimetrically by weighing the precipitated polystyrene chains.

\section{References}

1. Brennecke J.F. (1997) Solvents: molecular trees of green chemistry. Nature, 389, 333-334.

2. Clark J.H. (Ed) Rhodes C.N. (2000) Clean Synthesis Using Porous Inorganic Solid Catalysts and Supported Reagents. Royal Society of Chemistry, RSC, Cambridge.

3. Biedrón T., Kubisa P. (2004) Cationic polymerization of styrene in a neutral ionic liquid. $J$. Polym. Sci., Part A: polym. Chem., 42, 3230-3235.

4. Ma H., Wan X., Chen X., Zhou Q.F. (2003) Reverse Atom Transfer Radical Polymerization of Methyl Methacrylate in Room-Temperature Inoic Liquids. J. Polym. Sci., part A: Polym. Chem., 41, 143-151.

5. Mastrolliri P., Nobile C.F., Gallo V., Suranna G.P., Farinola G. (2002) Rhodium(I) catalyzed polymerization of phenylacetylene in ionic liquid. J. Mol. Catal. A: Chemical. 184, 73-78.

6. Vijayaraghavan R., Pringle J.M., MacFarlane D.R. (2008) Anionic polymerization of styrene in ionic liquids. Eur. Polym. J., 44, 1758-1762.

7. Marechal J.M., Carlotti S., Shcheglova L., Deffieux A. (2003) Stereoregulation in the anionic polymerization of styrene initiated by superbases. Polymer, 44, 7601-7607.

8. Carlotti S., Desbois P., Warzelhan V., Deffieux A. (2009) Retarded anionic polymerization (RAP) of styrene and dienes. Polymer, 50, 3057-3067.

9. Carlotti S., Menoret S., Barabanova A., Desbois P., Deffieux A. (2007) Sodium hydride as a new initiator for the retarded anionic polymerization (RAP) of styrene. Polymer, 48, 4322-4327.

10. Belbachir M., Bensaoula A. (2001) Composition and method for catalysis using bentonites. US Patent 6, 274, 527, B1.

11. Ferrahi M.I., Belbachir M. (2007) Cyclic polyesters prepared by poly(oxypropylene oxymaloyl) ring-chain reactions. eXPRESS Polym. Letters, 1, 24-26.

12. Rieger J. (1996) The glass transition temperature of polystyrene. J. Therm. Anal., 46, 965-972.

13. Amr, I. T., Al-Amer, A., Al-Harthi, M., Girei, S. A., Sougrat, R., Atieh, M. A. (2011) Effect of acid treated carbon nanotubes on mechanical, rheological and thermal properties of polystyrene nanocomposites. Composites: Part B, 42, 1554-1561. 